\title{
Article \\ Productivity-Based Land Suitability and Management Sensitivity Analysis: The Eucalyptus E. urophylla $\times$ E. grandis Case
}

\author{
Miaoying Shi ${ }^{1}$, Jintao $\mathrm{Xu}^{2}$, Shilei $\mathrm{Liu}^{3}$ and Zhenci $\mathrm{Xu}{ }^{4,5, *}$ \\ 1 School of Social and Public Administration, East China University of Science and Technology, Xuhui District, \\ Shanghai 200237, China; shimiaoying@ecust.edu.cn \\ 2 National School of Development, Peking University, Beijing 100871, China; xujt@nsd.pku.edu.cn \\ 3 School of Environment \& Natural Resources, Renmin University of China, Beijing 100872, China; \\ lius12021@ruc.edu.cn \\ 4 Department of Geography, The University of Hong Kong (HKU), Hong Kong 999077, China \\ 5 HKU Shenzhen Institute of Research and Innovation, Nanshan District, Shenzhen 518057, China \\ * Correspondence: xuzhenci@hku.hk
}

check for updates

Citation: Shi, M.; Xu, J.; Liu, S.; Xu, Z. Productivity-Based Land Suitability and Management Sensitivity Analysis: The Eucalyptus E. urophylla $\times$ E. grandis Case. Forests 2022, 13, 340. https://doi.org/10.3390/ f13020340

Academic Editor: Juan A. Blanco

Received: 18 December 2021

Accepted: 15 February 2022

Published: 18 February 2022

Publisher's Note: MDPI stays neutral with regard to jurisdictional claims in published maps and institutional affiliations.

Copyright: () 2022 by the authors Licensee MDPI, Basel, Switzerland. This article is an open access article distributed under the terms and conditions of the Creative Commons Attribution (CC BY) license (https:// creativecommons.org/licenses/by/ $4.0 /)$.

\begin{abstract}
Eucalyptus plantations are productive and short rotation forests prevalent in tropical areas that experience fast expansion and face controversies in ecological issues. In this study, we perform a systematic analysis of factors influencing eucalyptus growth through plot records from the National Forest Inventories and satellite images. We find primary restricting factors for eucalyptus growth via machine learning algorithms with random forests and accumulated local effects plots, as conventional forest growth models are inadequate to calculate the causal effect with the large number of environmental and socioeconomic factors. As a result, despite common belief that temperature affects eucalyptus growth the most, we find that precipitation is the most evident restricting factor for eucalyptus growth. We then identify and rank key factors that affect timber growth, such as tree density, rotation period, and wood ownership. Finally, we suggest optimal management and planting strategies for local farmers and policymakers to facilitate eucalyptus growth.
\end{abstract}

Keywords: land suitability; management sensitivity; forest plantation; timber volume; machine learning

\section{Introduction}

Planting forests is becoming a necessary and indispensable part in various ecosystem restoration and rural development contexts as forests play roles in conservation, recreation, carbon sequestration, timber, food, and fuel provision [1-6]. The scope of the plantation has been increased with greenhouse gas emissions, population expansion, and mass consumption of materials and energy lead to environment degradation, resource depletion and species extinction.

Eucalyptus is a short-rotation hardwood species which has been a popular plantation species worldwide for provisioning some environmental services and providing high quality pulp and veneer sheets $[7,8]$. Managing such valuable species for both economic and environmental sustainability requires a comprehensive understanding of the underlying linkage between site conditions and forest growth performances.

The benefits and progresses of eucalypt plantations are paralleled with concerns and doubts. As eucalyptus was introduced from Australia, the identity of "foreign species" makes eucalyptus an appropriate species for assessing how trees adapt to land use and climate effects in local countries [9-11]. For example, eucalyptus is a water-intensive species and could possibly lead to water depletion in the local region [12,13]. In the case of China, Eucalyptus prevails in Guangxi province (region), where the largest eucalyptus plantation in China resides, local farmers and policymakers believe that eucalyptus productivity will 
be lower at the northern area of $24^{\circ}$ latitudes. Farmers believe that the accumulated temperature of $24^{\circ}$ north latitudes is insufficient $[9,14]$. Different perceptions make eucalyptus suitable as a sentinel species for ecological suitability analyses.

Ecological suitability varies in complexity because of site conditions and management factors. The primary objective of this study is to analyze eucalyptus growth and determine the condition and extent for suitable land use area. Previous studies attempting this problem face the following limitations: firstly, a large forest growth dataset with rich attributes and high consistency is required to represent land/site conditions and management regimes; secondly, with a large set of indicators, it is not realistic to identify causal inferences based on conventional analytical methods, and therefore, a robust and flexible analyzing tool is essential to include various ecological and social-economic factors; thirdly, to empower local farmers and to help policymakers make decisions, visual representations of suitability or productivity maps as well as growth responses are needed.

In order to accurately describe eucalyptus growth's relationship with respect to various factors, we acquire a dataset from the National Forestry Inventory (NFI) in Guangxi province, as Guangxi has the largest eucalyptus plantation area in China. The NFI data have a common plot design and a consistent data collection procedure nationwide. Meanwhile, NFI includes various data attributes related to plot information and management regimes. Meteorological, pedological, and topological information are acquired from publicly available satellite products. With pooling of the data, machine learning algorithms are employed to examine the factor importance. We compute the growth changes with respect to the variation of all site conditions and management regimes. In order to give hands-on information for local farmer and policymakers, we produce regional productivity maps. We believe that a large dataset equipped with high quality and rich information could render a more inclusive understanding of the relationships between forest growth and the complex interactions with the environment conditions, providing implications for generating better options for improved resource management and increasing the reliability of forecasting the outcomes from different conditions of forest land.

The remainder of this paper is organized as follows. We first describe the method and data used. The results section then discusses individual factor effects and interaction effects between key factors, as well as predicting the productivity map. The final section presents conclusions and limitations.

\section{Materials and Methods}

In order to disentangle the inherent relationships between forest growth and environment conditions, it is necessary for forest managers and planners to have access to the full picture of the interactions between stand conditions and forest growth. Conventional growth and yield model provides the underpinning basis for timber supply estimation, but these models are also limited in their flexibility to accommodate a range of growth factors, such as site conditions and management regimes $[15,16]$. Econometric estimation methods are also inadequate to estimate the cause-effect relationships with the huge number of environment and socioeconomic factors $[17,18]$. Moreover, non-linear dependences of growth response to socio-ecological indicators require more flexible estimators for controlling unobserved confounds.

Machine learning is a valuable tool to help remedy this situation by providing sufficient decision-making suggestions [19,20]. A variety of machine-learning algorithms are with wide applications, for example, decision tree, support vector machine, k-nearest neighbors, gradient boosting algorithms, random forest, etc. Among these algorithms, random forest has gained wide popularity due to its flexibility of identification and recognition in the complex structures [21,22]. As one of the most accurate learning algorithms available $[17,23-25]$, random forest not only helps discover the variable dependencies but also improves the predictive power while accounting for the underlying interaction effects $[26,27]$. 
For model selection, at the starting point, we fit a variety of machine-learning algorithms (support vector machine, k-nearest neighbors, gradient boosting algorithms and random forest), and finally, we employ the random forest model as it produces the smallest residual among various algorithms tested. We use hyperparameter tuning to train the random forest model in order to arrive at the best performing model. In order to extract the key factors and reduce overfitting, we employ the feature selection method built into the random forest model that suits non-linear relationships among ecological attributes/features. We start out by ranking the relative importance of each attribute based on its accuracy of timber volume prediction. We then use the automatic method of recursive feature elimination (RFE) to explore the best possible subsets of the attribute.

The random forest model is inherently capable of handling interaction effects, especially in the case with large forests [28]; thus, there is no need to include interaction terms in the model. We employ an accumulated local effect (ALE) plot to account for individual feature (factor) effects, as well as interaction effects [29,30]. The ALE plot describes the average marginal effect on the prediction by varying the values of the factor(s) of interest. ALE function estimates local effects by dividing the factor values into intervals based on quantiles and computes the effect each factor value has within the interval. By aggregating the average effects across all intervals, the ALE plot leads to a more stable estimation compared to traditional techniques [29]. The ALE plot is integrated in several R packages, such as caret and $\mathrm{mlr}$, and most of them compute the individual (first-order) and interaction (second-order) effect separately [30,31]. In addition, we also used sp (Version: 1.4-6) and rgdal (Version: 1.5-28) packages for spatial data extraction, randomForest package (Version: 4.7-1) for data analysis and ggplot2 package (Version: 3.3.5) for plotting graphs [32-35].

Ecological suitability analysis is generally based on site-productivity evaluations $[36,37]$. Estimates of site-based productivity should be comprehensive and accurate as interaction effects and biases propagate and affect modelling performances and subsequent forecasting results [38,39].

In order to represent the site condition and perform land-productivity analysis of Guangxi, we acquire raster data including: thematic data, including land-use and soils data, mapping the potentially suitable area for eucalyptus plantation; continuous data, such as topographical features (elevation, aspect, slope, etc.), meteorological situations (temperature and precipitation situations) and other factors, characterizing site conditions that would make differences in timber productivity.

Aside from the publicly available raster data, we also acquire the spatially referenced plot-based National Forest Inventory (NFI). The NFI carries systematic information and records the true productivity in situ, which allows for sound wood-growth estimations and comparisons [40,41]. Important attributes in the NFI include plot area, site quality, tree age, stem density, diameter at breast height (DBH), height, institutional arrangement and management regimes information (land ownership, tree ownership, etc.). These are essential and complementary to the previous dataset. Moreover, the NFI dataset includes spatially extensive plantation patches, among which 4798 samples are E. urophylla $\times$ E. grandis, which is one of the most prevalent eucalyptus species in China. Figure 1 below shows the study area in which the black dot stands for the centroid of UG plot. The large sample size and comprehensive information of NFI allows for accurate assessments of the relationships between timber yields and forest factors. These newly found relationships coupled with the terrain and surface information enable us to determine the spatial extent of eucalyptus plantation and to obtain precise assessments of its condition, growth, volume, etc. 


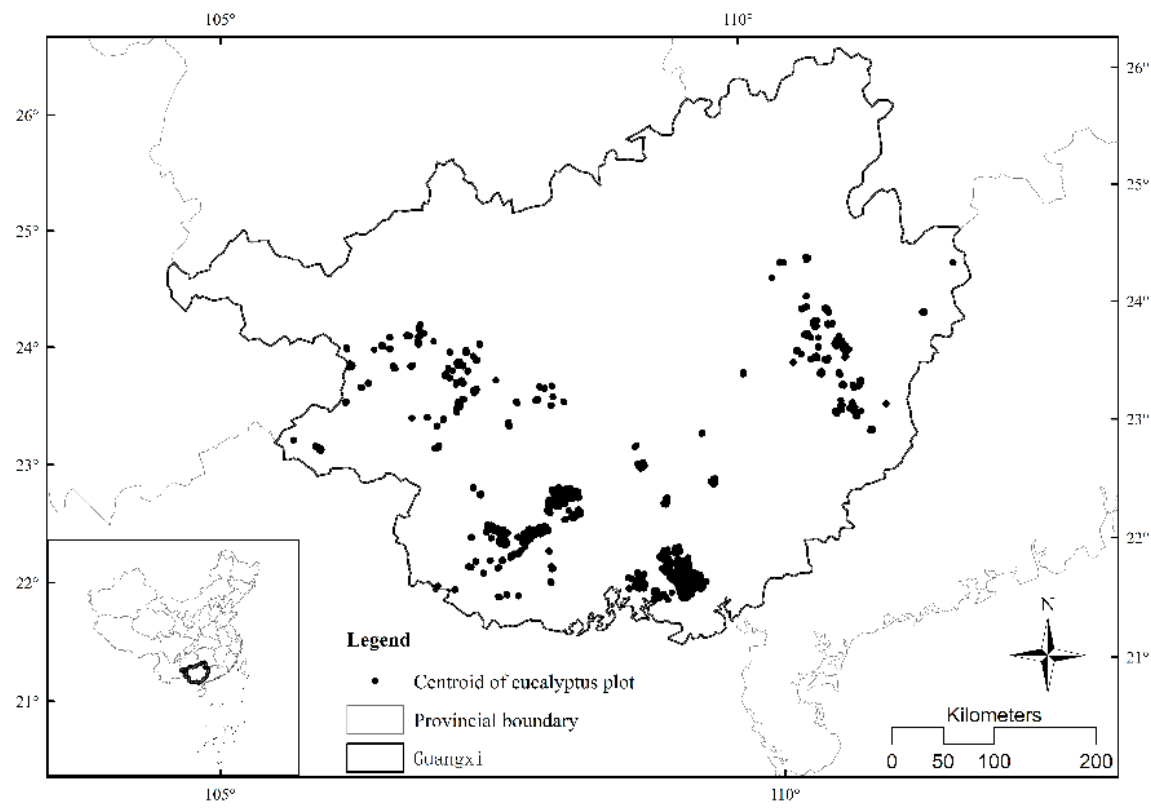

Figure 1. E. urophylla $\times$ E. grandis study area in Guangxi.

The NFI data are of high dimension, and we also extracted a series of information from raster data; those highly correlated variables are identified and removed based on correlation matrix. Table 1 below presents the variables and related information.

Table 1. Descriptive statistics for further feature selection in random forest.

\begin{tabular}{|c|c|c|c|c|}
\hline Factors & Variables & Min & Max & Unit \\
\hline \multirow{2}{*}{ Coordinates } & latitude & 21.85 & 24.61 & degree \\
\hline & longitude & 105.67 & 111.88 & degree \\
\hline \multirow{3}{*}{ Topographic factors } & altitude & 60 & 1240 & meters \\
\hline & Aspect & factor & factor & none \\
\hline & slope & 5 & 43 & degree \\
\hline \multirow{2}{*}{ Meteorological factors } & accumulated_temperature & 61,563 & 80,160 & $0.1^{\circ} \mathrm{C}$ \\
\hline & precipitation & 11,036 & 17,771 & $0.1 \mathrm{~mm}$ \\
\hline \multirow{2}{*}{ pedological factors } & soil * & factor & factor & none \\
\hline & soil_depth * & 1 & 128 & $\mathrm{~m}$ \\
\hline \multirow{3}{*}{ Ownerships } & land_ownership * & factor & factor & none \\
\hline & land_management_right * & factor & factor & none \\
\hline & tree_ownership & factor & factor & none \\
\hline \multirow{5}{*}{ Management status } & plot_area & 0.1 & 47.3 & hectare \\
\hline & tree_density & 300 & 3000 & stem/hectare \\
\hline & tree_age & 1 & 10 & year \\
\hline & regeneration & factor & factor & none \\
\hline & health_condition * & factor & factor & none \\
\hline Productivity & timber_volume & 0 & 0.55 & cubic meter \\
\hline
\end{tabular}

Notes: (1) variables with asterisk are not included in the final model. See feature selection in the results section below. (2) The variable of aspect contains 9 categories, including eight directions and an unknown category, that is, north, northeast, east, southeast, south, southwest, west, northwest and unknown; (3) soil contains 11 categories, including laterite, limestone, paddy soil, purple soil, red clay, red soil, skeletal soil, soil lime, yellow soil, yellowbrown soil, and others; (4) land_ownership contains 2 categories, including collective-owned and state-owned; (5) land_management_rights contains 5 categories, including collective, forestry bureau, overseas enterprises, state-owned enterprises (SOEs), and unclear; (6) tree_ownership contains 6 categories, including collective, forestry bureau, joint operation, overseas enterprises, private, and SOEs; (7) regeneration contains 4 categories, including planting, 1st coppice, 2nd coppice, and 3rd coppice; (8) health_condition contains 4 categories, including healthy, medium healthy, sub-healthy, and unhealthy. 


\section{Results}

\subsection{Feature Importance Ranking in Impacting Timber Growth}

We employed hyperparameter tuning to train the random forest model in order to arrive at the best performing model. We used a 100-repeated fivefold cross-validation resampling setting. Based on the out-of-bag (OOB) estimate [42], the mean of squared residuals between the observed and predicted timber volume is $0.000232 \mathrm{~m}^{3} /$ tree. As a result, the hyperparameter tuning suggests that the number of optimal randomly sampled variables is 7 with a sampling fraction of 0.289 and a minimum final node size of 3 . According to RFE, the most important features are the top ranking 12 attributes shown in Figure 2, while the remaining variables are redundant in timber volume estimation.

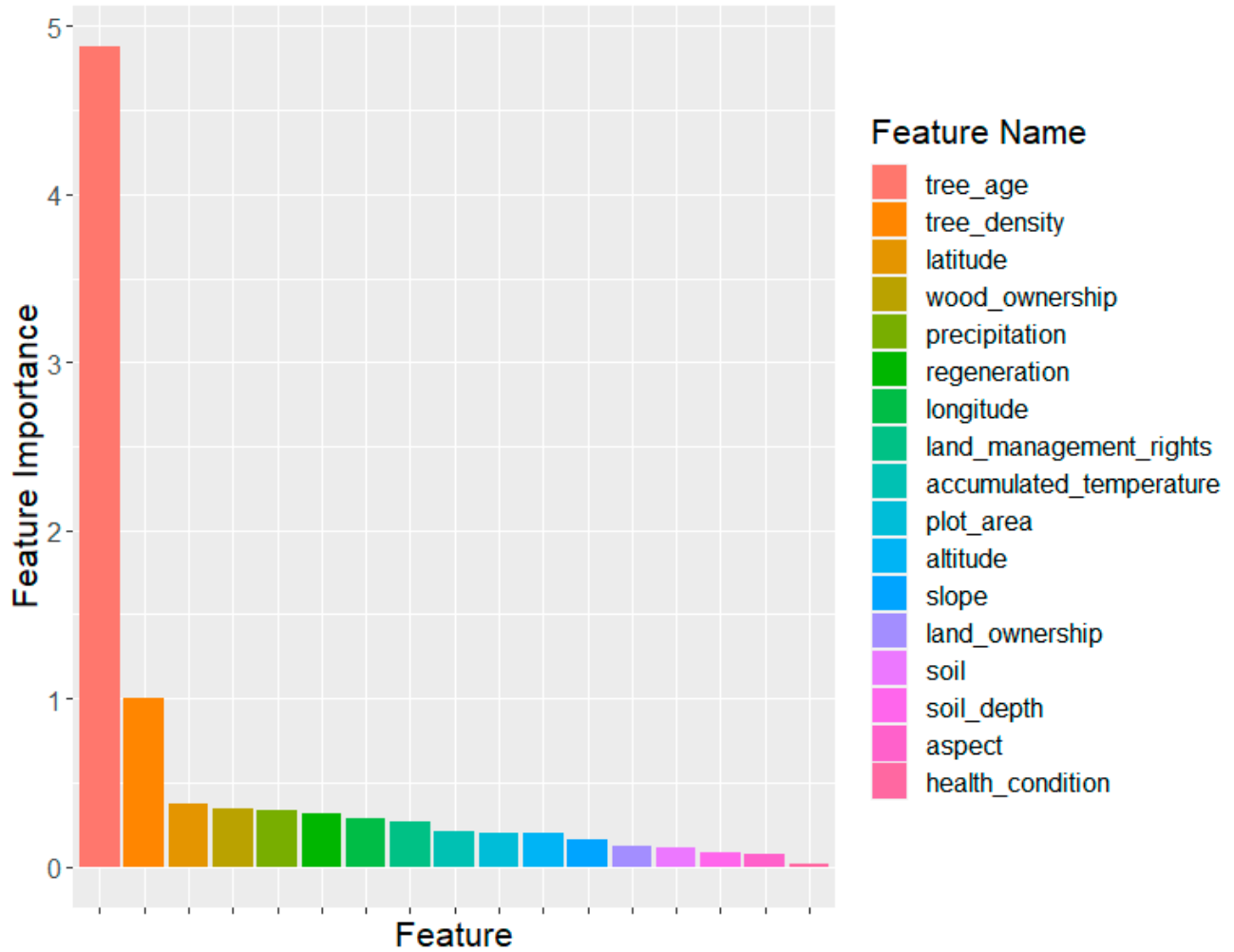

Figure 2. The top 12 variables in feature importance ranking.

Figure 2 reports the relative importance of growth factors. The factor of most vital importance in estimating timber volume is tree age whose effect far exceeds all other variables. The results also highlight the importance of management choices of stem density, which is subsequently followed by the latitudes of each plot. Annual precipitation has a strong influence in affecting eucalyptus growth, making it higher in ranking compared to accumulated temperature. This information is of great value for local farmers as it contradicts the common perception that the primary limitation of eucalyptus growth is cold temperatures in the northern area of 24 degrees in latitude. Our results demonstrate that, within Guangxi province, a restricting natural factor that is great importance is precipitation. This finding is further investigated in a later analysis (see Sections 3.2 and 3.3).

\subsection{Individual Factor Effects in Affecting Timber Growth}

ALE plots provide a useful tool for investigating the responses of timber growth to forest factor variations. The individual effect plots demonstrate that timber volume is affected by tree age and stem density. The black blocks on the horizontal axis indicate data abundance while the value on the vertical axis indicates the individual effects of forest factors. From Figure 3, we can see that the average timber volume prediction rises as trees get older before the slope decreases around the age of 6 . This implies that the optimal 
rotation age is around 6 years old. Figure 3 presents an upward trend when the tree age is greater than 8 . We believe that these samples are from the experimental fields as most eucalyptus trees are harvested before they reach 6 years of age in Guangxi. Meanwhile, the prediction based on stem density in Figure 4 suggests that the average timber volume rises with increasing density before reaching the turning point of 1000 trees per hectare; after that, higher density leads to a lower predicted volume for a single tree on average.

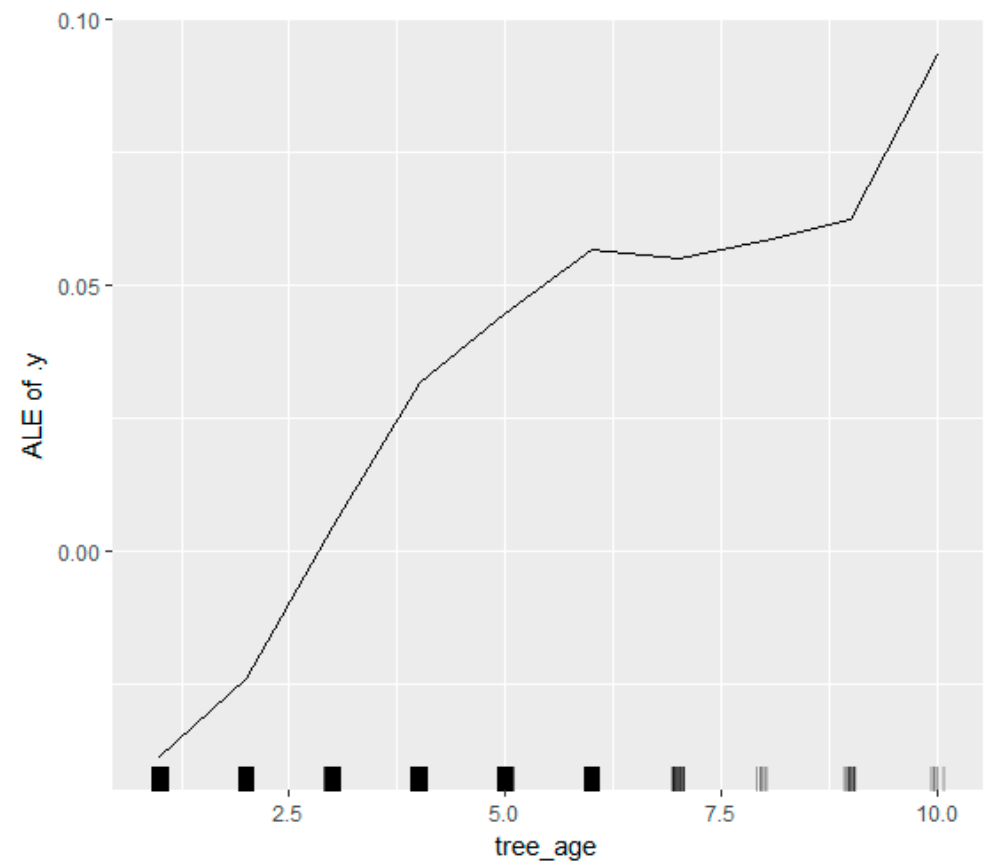

Figure 3. ALE plot of tree age.

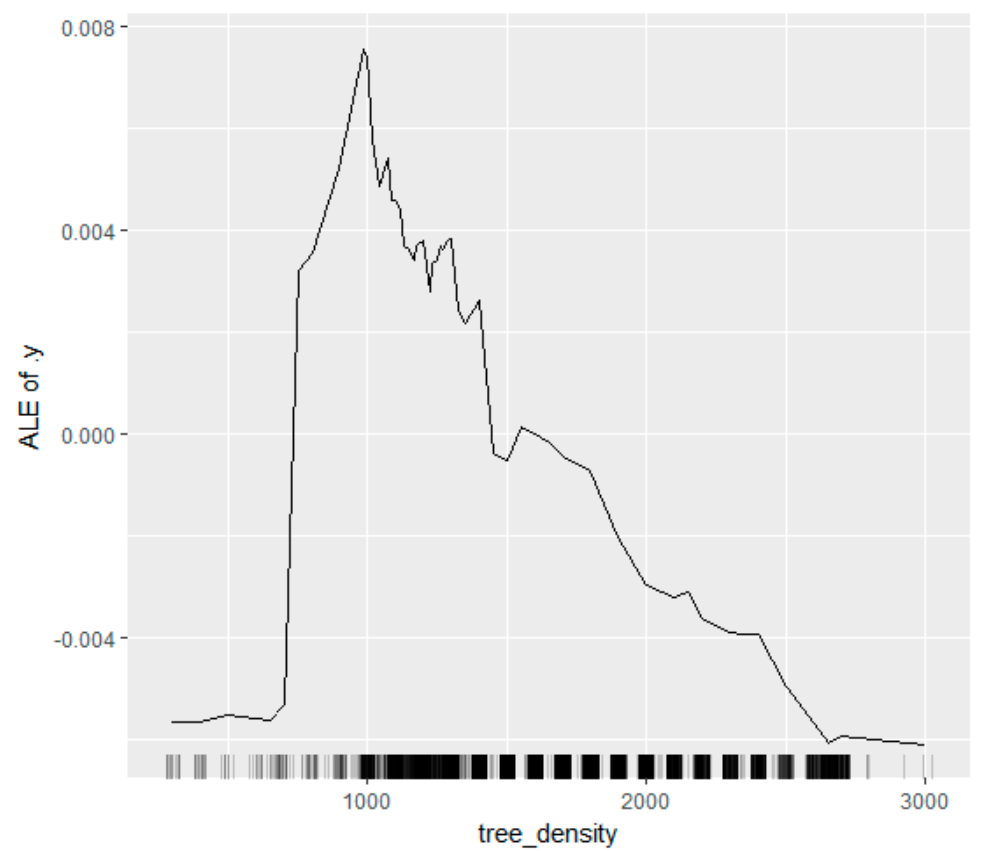

Figure 4. ALE plot of stem density.

The first-order effect plots in Figure 5 demonstrate timber productivity prediction by altitude. Altitude has a strong effect on timber productivity. Overall, the ALE plot in Figure 5 identifies that timber volume falls with increasing altitude and the tipping point occurs at the altitude of $250 \mathrm{~m}$. In Figure 6, we extract aspects at the centroid of 
each plantation plot; therefore, the ALE plots are based on categorical features; we observe that tree plots facing to the south or close to south aspects tend to have higher effects on the predicted timber volume. As shown in Figure 6, trees grown on the aspects that face the south (S), southeast (SE), and southwest (SW) share above-average predicted volumes while trees grown on the northeast (NE), northwest (NW), and east share below-average timber volumes.

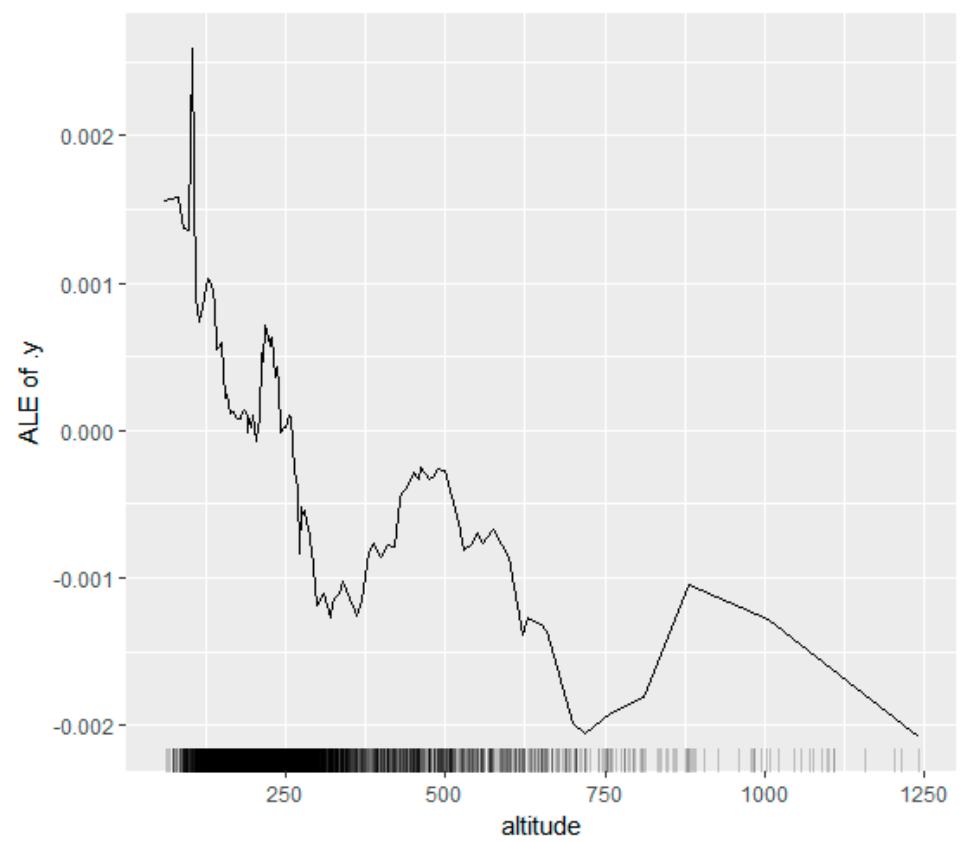

Figure 5. ALE plot of altitude.

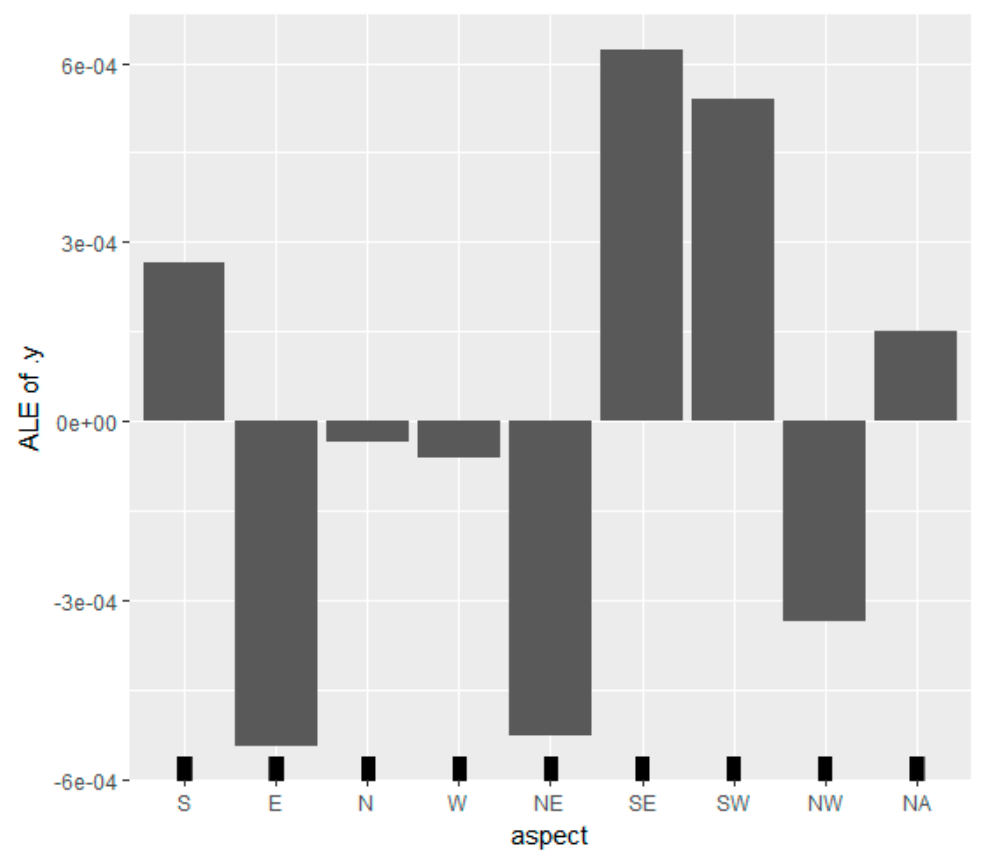

Figure 6. ALE plot of aspect.

Figure 7 implies that the forest productivity consistently increases with the increase in plot area. During the decentralization of forest land rights, private forest owners tends to have more fragmented forestland, while larger forest management corporations and organization who have stronger capital power usually buy the land management rights from local forest owners, resulting in a larger area of forest plots; from Figure 7, it could be seen 
that larger forest plots, which are potentially better managed, turned out to have greater productivity. This situation is also confirmed in the tree-ownership plot in Figure 8: based on the histograms, forests managed by state-owned enterprises and overseas companies have relatively larger timber volume while forests owned by private, local communities (collectively owned) generally have lower forest productivity. One thing that needs to be noted here is that the forest plots belonging to forestry bureaus do not necessary performs better than those owned by overseas corporations, and neither do those belonging to joint operated unions (cooperated by different economic organizations).

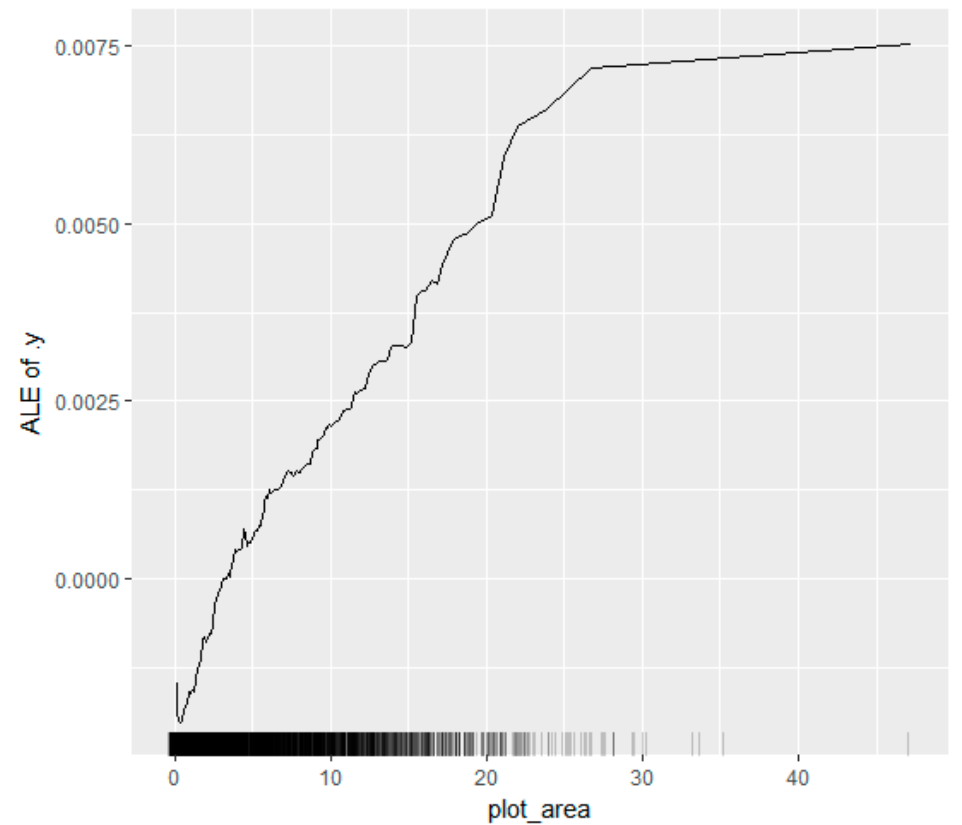

Figure 7. ALE plot of plantation area.

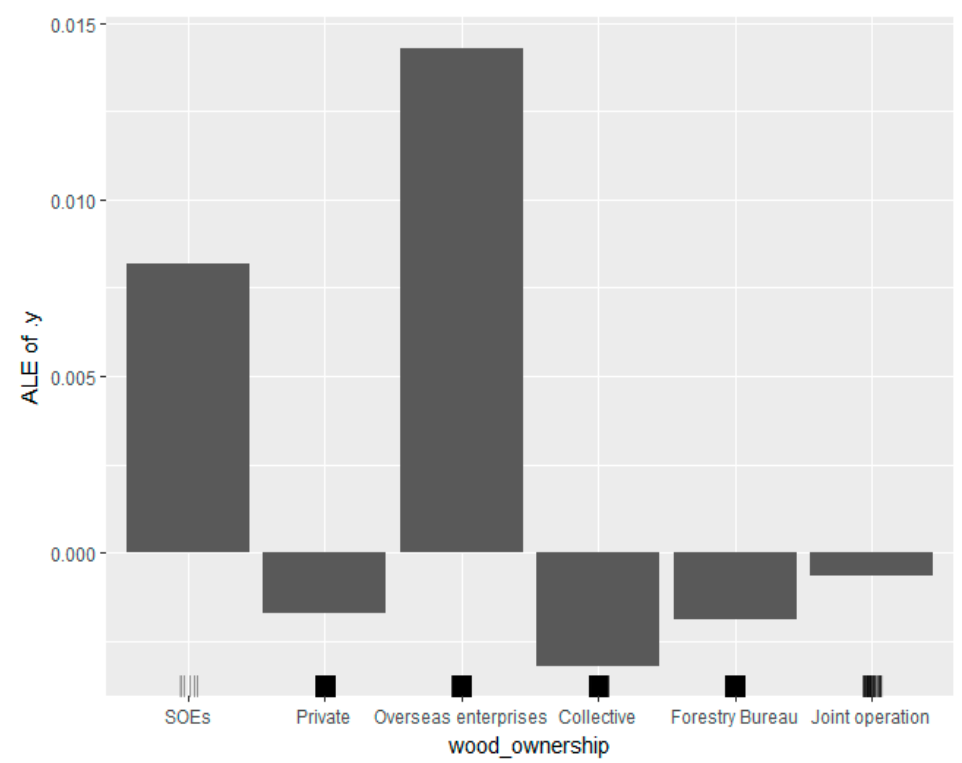

Figure 8. ALE plot of tree ownership.

The land slope also has some impact, though not strong, on the forest productivity. According to Figure 9, land with aslope ranging from 15 to 26 degrees has great productivity in general. As we have limited samples for land whose slope is greater than 30 degrees, the results in this range are not reliable. 


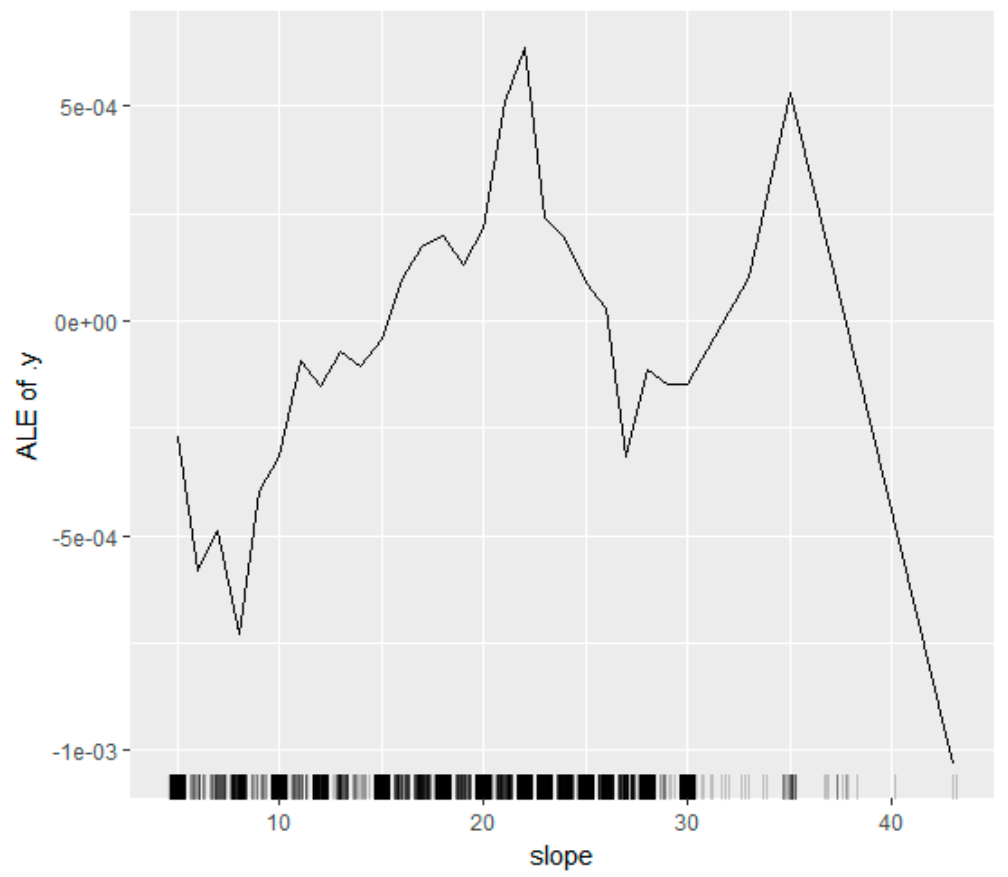

Figure 9. ALE plot of plantation slope.

We continue to examine the response of forest productivity to regeneration methods. The results in Figure 10 indicate that the overall direct impact of regeneration methods is trivial as the value of the vertical axis is very close to zero. In contrast, planting forests do not necessarily out-perform forests generated from coppices in terms of timber volume. The first-generation coppice tends to experience lower productivity compared to the second and third coppices.

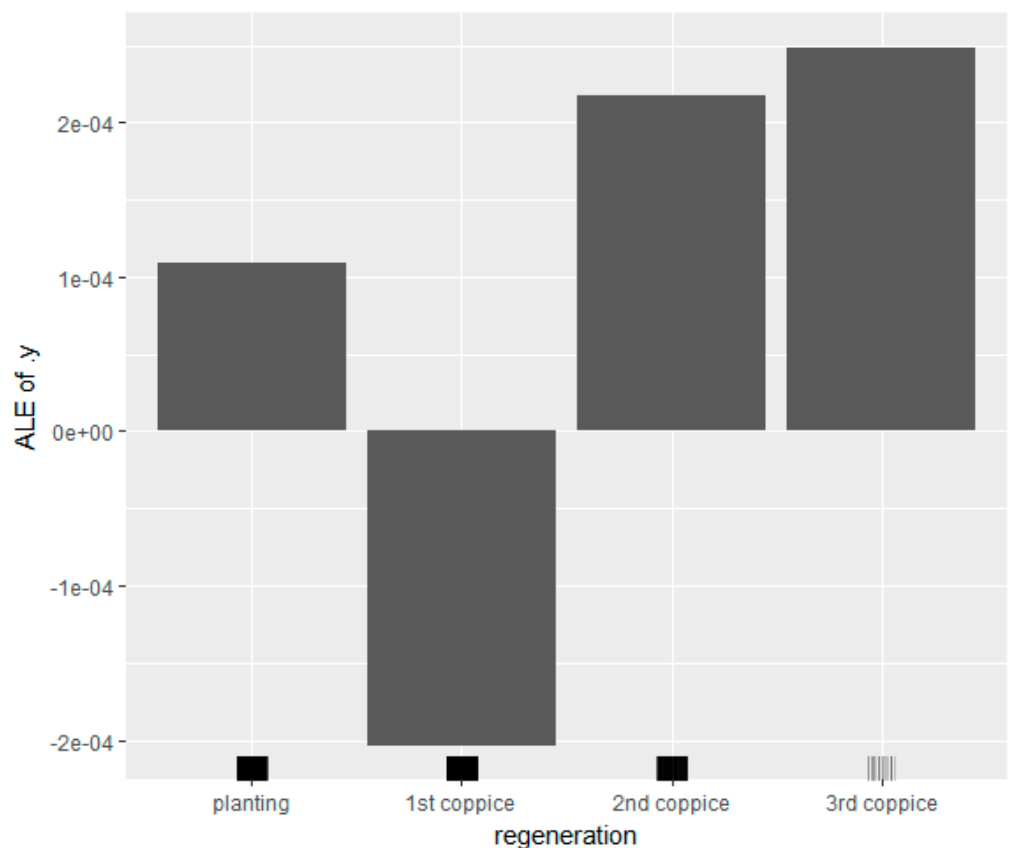

Figure 10. ALE plot of regeneration methods.

\subsection{Interaction Effects between Forest Factors in Affecting Timber Growth}

The interaction effects between certain factors could enhance/or decrease growth rate, thus potentially improving / or reducing the total timber output. Though the random forest method is noted for its ability to account for the underlying interaction effects [26-28], it 
would be fruitful to examine the interaction effects explicitly between factors for a better understanding of the ecological suitability of eucalyptus. Figure 11 below presents the joint plot of the interaction effects between one factor and the remaining variables in influencing the timber growth. The interaction effect is the additional change in the prediction after considering the individual (main) effects. It is straightforward to see that the overall interaction strength in Figure 11 represents a close pattern to the feature importance graph in Figure 2. The interaction effect between tree age and the rest of the features is especially strong. Similarly, the overall interaction strength based on the other features with latitude, tree density, precipitation, and accumulated are all in close sequence with those features in Figure 2, making these top-ranking features a high priority for further examinations.

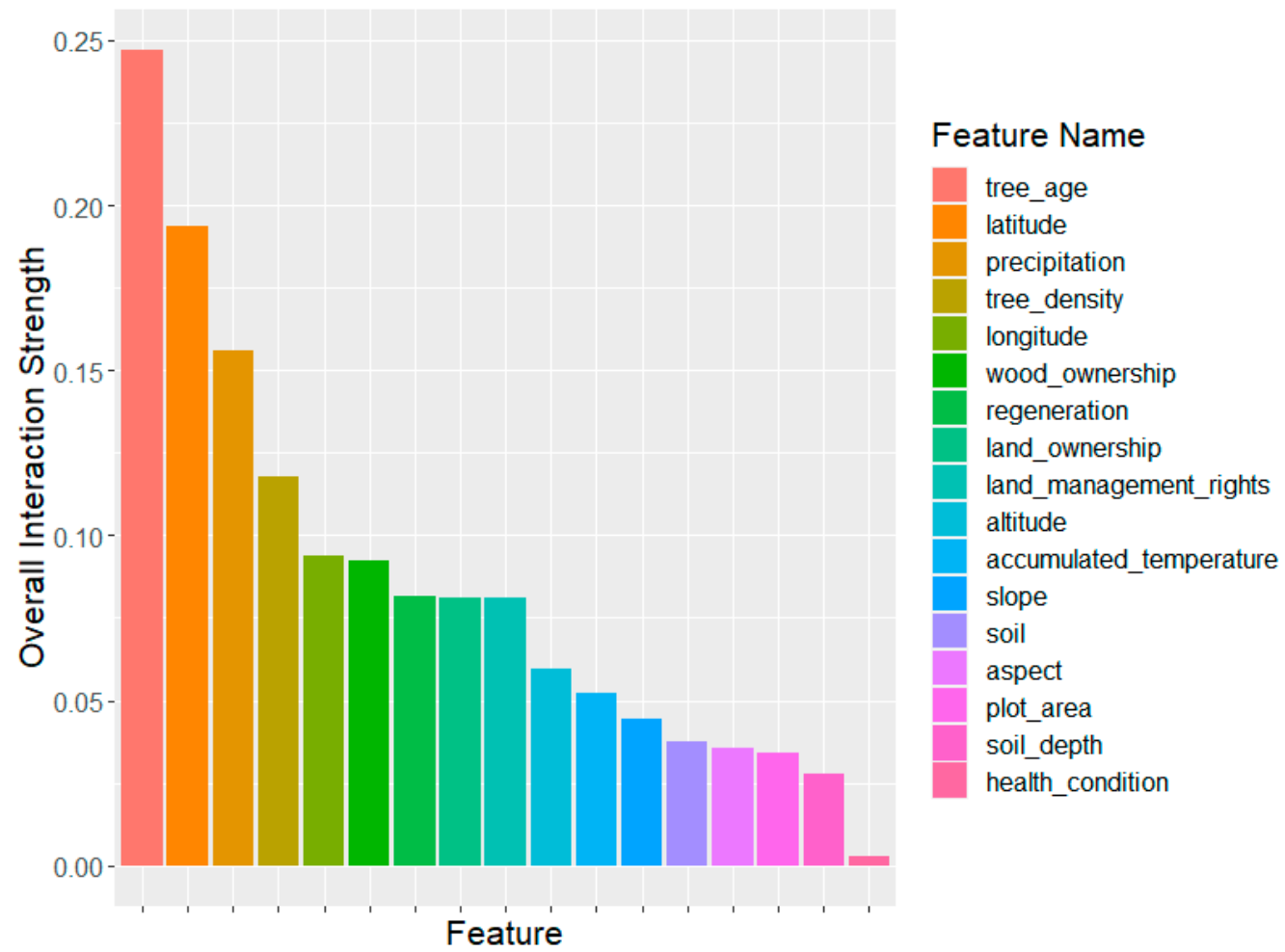

Figure 11. Overall interaction strength ranking based on one feature and the remaining variables.

We derived the ALE interaction effect plots for each feature in Figure 11 and drew the related interaction map for features with high rankings. The interaction effects between two factors are the net changes in the prediction that caused by the factor value variation after considering the individual effects. These interaction maps provide intuitive interpretations of interaction effects; due to the large number of maps, we generated the magnitude of the interaction effect and listed them in Table 2. The three highest interaction effects are all between variables and latitude: precipitation and latitude, longitude and latitude, and accumulated temperature and latitude. We report a productivity map associated with latitude and longitude in Section 3.4. 
Table 2. Interaction relationships between crucial forest factors.

\begin{tabular}{cccc}
\hline Site Factor $\mathbf{1}$ & Site Factor $\mathbf{2}$ & Interaction Effect & Ranking \\
\hline Precipitation & Latitude & $(-0.2,0.0)$ & 1 \\
Longitude & Latitude & $(-0.05,0.10)$ & 2 \\
Accumulated temperature & Latitude & $(-0.03,0.03)$ & 3 \\
Tree age & Stem Density & $(-0.02,0.02)$ & 4 \\
Stem Density & Latitude & $(-0.01,0.03)$ & 4 \\
Stem Density & Longitude & $(-0.01,0.02)$ & 6 \\
Precipitation & AccumTemperature & $(-0.01,0.02)$ & 6 \\
Longitude & Altitude & $(-0.01,0.02)$ & 6 \\
Precipitation & Altitude & $(-0.015,0.005)$ & 9 \\
Precipitation & Tree Density & $(-0.005,0.010)$ & 10 \\
Plot Area & Altitude & $(-0.004,0.002)$ & 11 \\
Precipitation & Slope & $(-0.002,0.003)$ & 12 \\
Accumulated temperature & Slope & $(-0.001,0.002)$ & 13 \\
\hline
\end{tabular}

Note: the unit of interaction effect is cubic meters per tree.

Figure 12 describes the ALE plot of timber growth with respect to latitude. As altitude change caused temperature changes has already been taken into consideration during the data-generation process (with altitude increase $100 \mathrm{~m}$, the average temperature decrease $0.6^{\circ} \mathrm{C}$ ), we will dig further into the annual precipitation and accumulated temperature as these two factors directly affect forest growth and will have important implications for future land adaptation in climate change contexts. In Figure 12, the average timber volume prediction rises with latitude goes to the northern region. There are productivity peaks in the range of $22.5-24^{\circ}$ whereas the line drops sharply after $24^{\circ}$, indicating great decline in productivity in the northern region in cold mountainous areas. Local farmers attribute the low productivity to the relatively low temperature. Meanwhile, the prediction based on longitude (Figure 13) suggests that the eucalyptus plantations located in the middle and east region out-perform those in the west region.

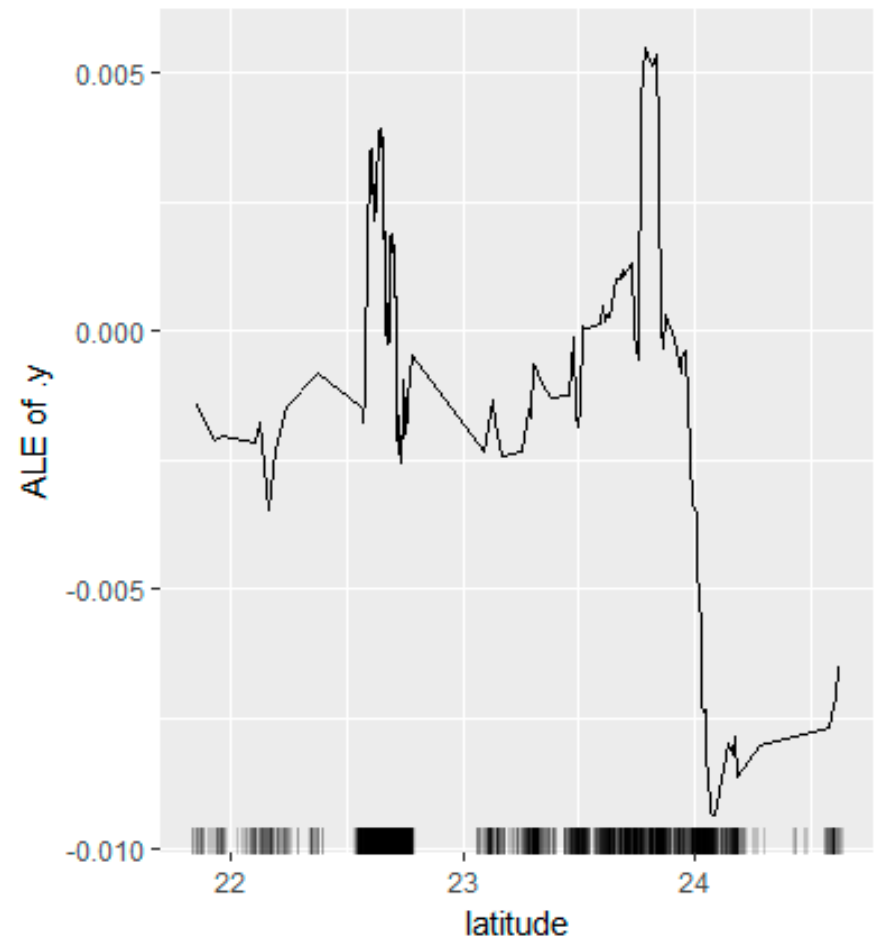

Figure 12. ALE plot of latitude. 


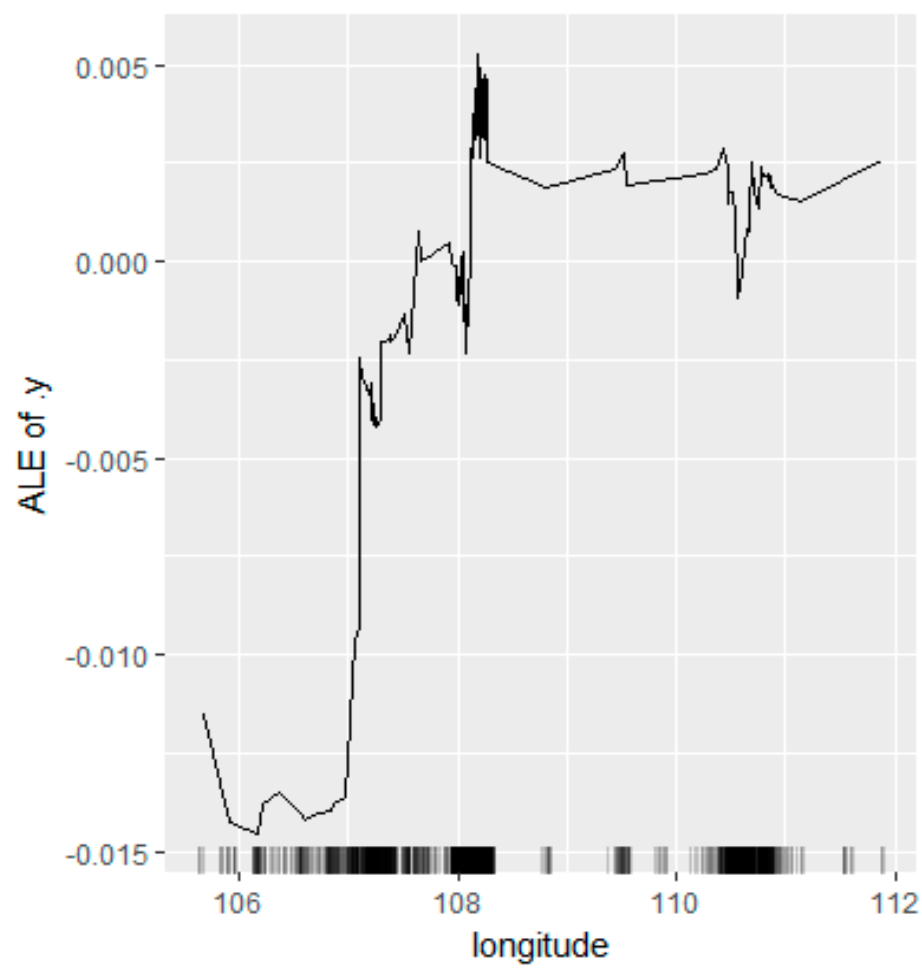

Figure 13. ALE plot of longitude.

According to Figure 14, there exists a minimum precipitation line near the precipitation level of $1200 \mathrm{~mm}$ /year. When the precipitation is lower than this level, the timber production fluctuates a lot, but when the rainfall succeeds $1200 \mathrm{~mm}$ /year, the timber production generally stays above average while varying a little. This minimum precipitation line is also confirmed in the interaction effect plot between precipitation and latitude in Figure 15, though the exact value varies. In Figure 15, due to the interaction effect between precipitation and latitude, when the annual precipitation is below $1300 \mathrm{~mm}$, there exists an extra negative effect on the volume prediction, especially when the plantation locates to 23.5 degrees north. To the contrary, when the precipitation is sufficient, interaction effects between these two factors do not show any disadvantages in timber growth. This indicates that a sufficient amount of precipitation could somehow mitigate the disadvantage of relative high latitude, and the magnitude of the mitigation effect can reach as much as 0.2 cubic meters.

The first-order effect plot based on accumulated temperature (baseline is $0{ }^{\circ} \mathrm{C}$ ) in Figure 16 suggests that the average timber volume generally increases with the increasing annual accumulated temperature. The average net volume increase could vary from -0.010 to about 0.005 (with a range of 0.015 ) cubic meters due to the change of accumulated temperatures. From the interaction plot between accumulated temperature and latitude (Figure 17), we can see that we have a limited sample size at the highlighted region when the accumulated temperature is below 7000 and the latitude is below $23^{\circ} \mathrm{N}$. As for the relatively darker area, even though we have sufficient samples, the color variation is small, which implies that there is no strong heterogeneity in the interaction effects between accumulated effects and latitude. 


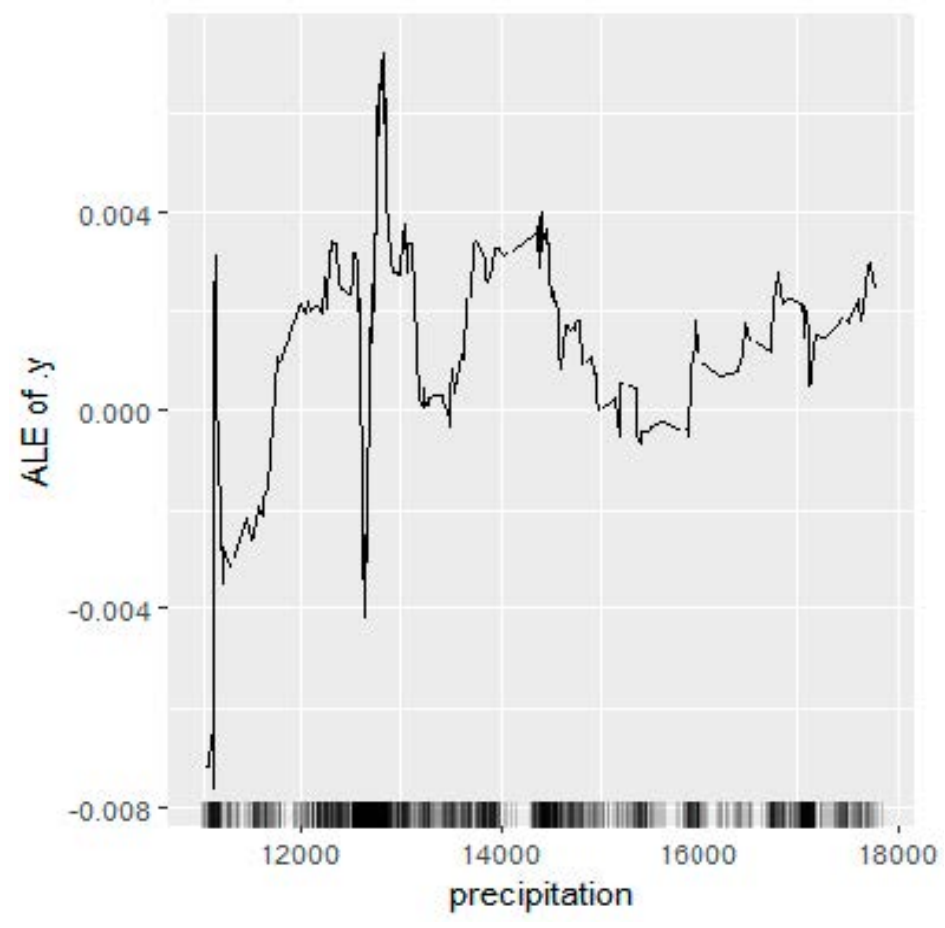

Figure 14. ALE plot of precipitation $(0.1 \mathrm{~mm})$.

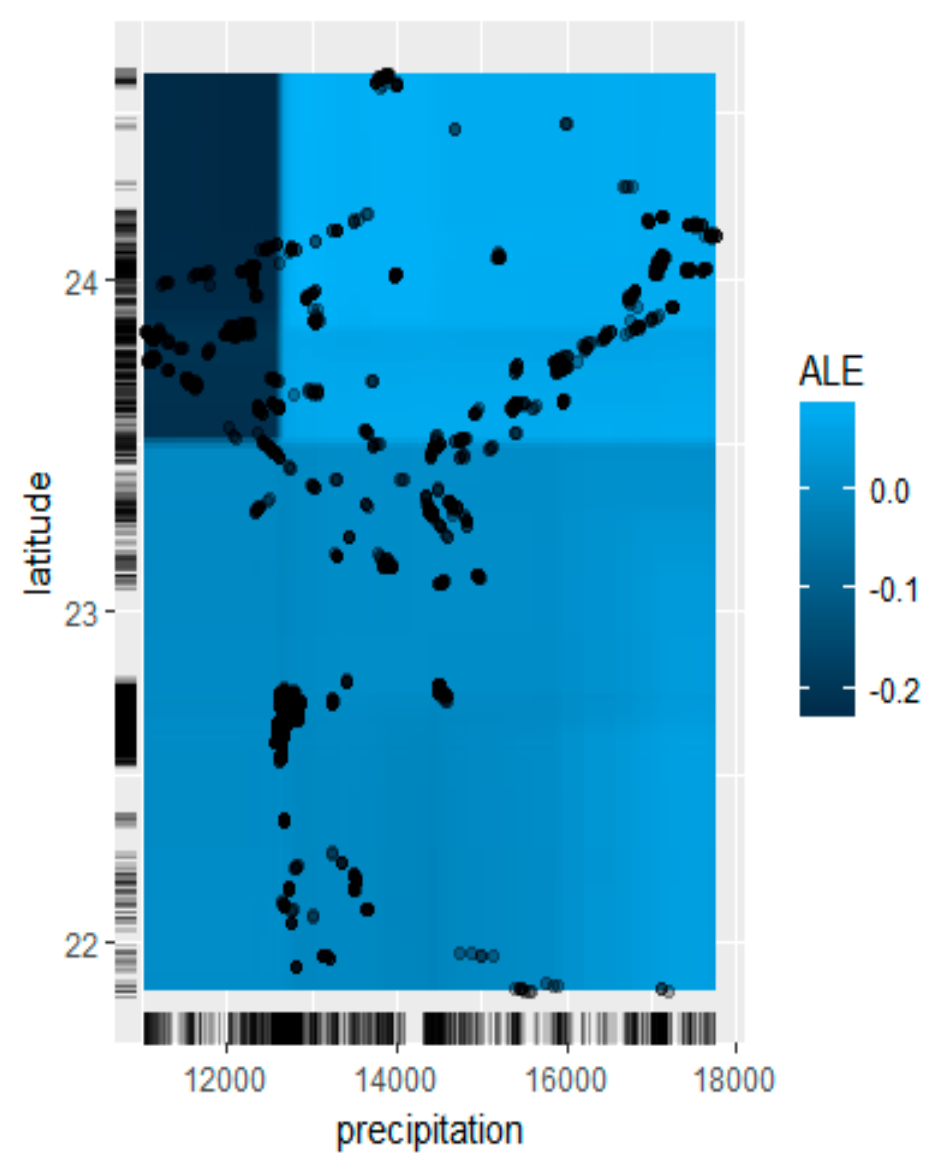

Figure 15. Interaction effects between precipitation and latitude. 


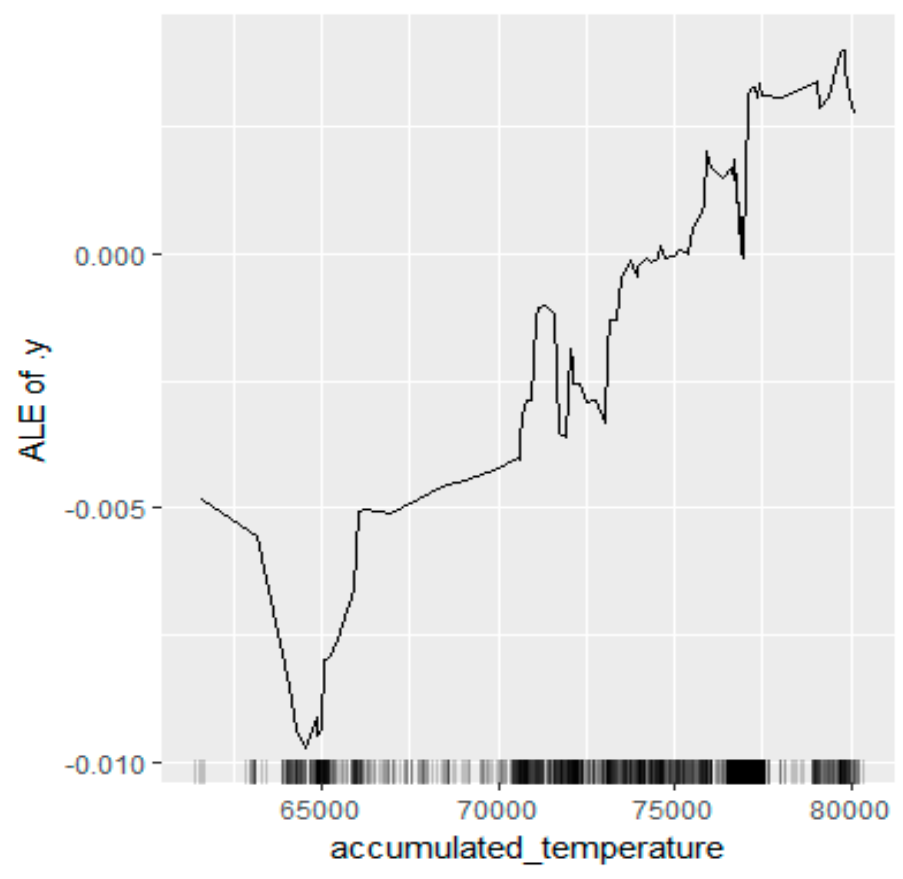

Figure 16. ALE plot of accumulated temperature $\left(0.1^{\circ} \mathrm{C}\right)$.

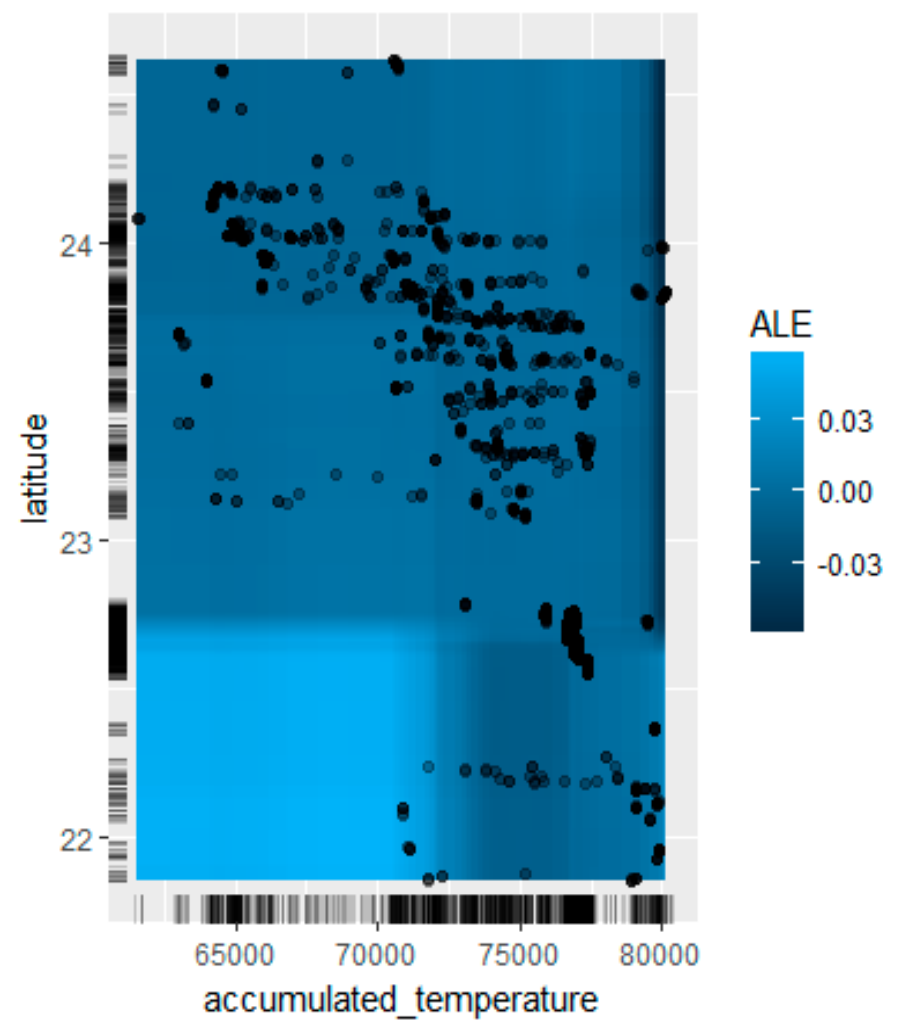

Figure 17. Interaction effects between accumulated temperature and latitude.

\subsection{Ecological Suitability and Eucalyptus Productivity}

Using the random forest model and rich environmental information from satellite images and the NFI growth data, we predict the eucalyptus productivity for the entire Guangxi province (see Figure 18 below). Topographic information (digital elevation model, $\mathrm{DEM}$ ) is integrated and proportionally enlarged into a $3 \mathrm{D}$ plot for better visualization. The value in Figure 18 denotes the predicted unit land productivity $\left(\mathrm{m}^{3} /\right.$ hectare) for a 5-6-year-old E. urophylla $\times$ E. grandis plot. We used the gradient from light yellow to 
dark blue to represent low to high timber productivity, where the white color stands for non-forested areas. The value in the scale details the corresponding productivity associated with each land, for example, the value of 114 in the scale suggests the lowest timber output for one hectare of land with eucalyptus harvested at the age randomly selected between the age of 5 and 6 years; meanwhile, the largest value of 227 stands for the maximum timber output predicted in the study region.

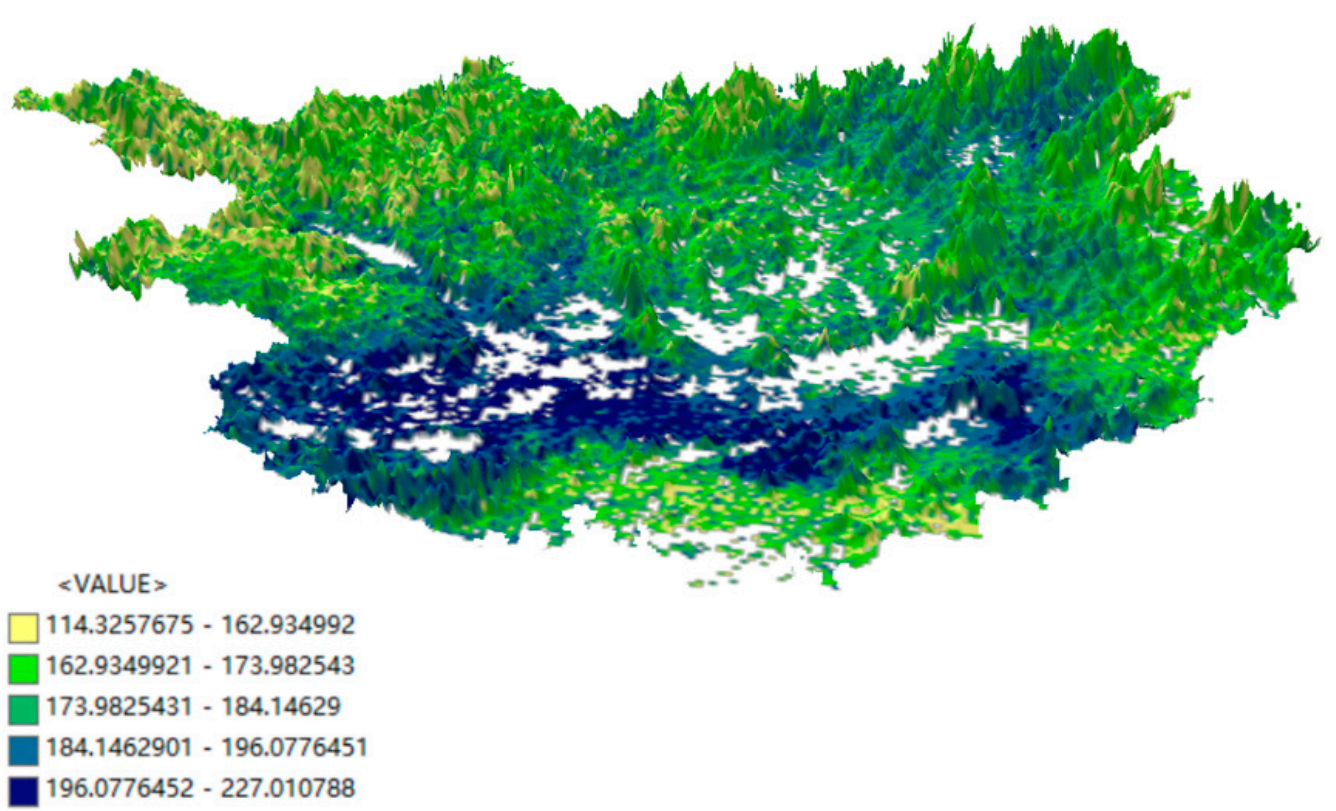

Figure 18. Ecological suitability and land productivity map for E. urophylla $\times$ E. grandis

In general, from Figure 18, we can see that the large block of dark blue is mainly centralized in the relatively flat regions in south Guangxi while the light-yellow color is largely spread across the northwest mountainous region. Eucalyptus in south Guangxi tends to have a better timber yield than those in the northern area; meanwhile, eucalyptus in the east region also has better productivity than in the west region. An important note is that, though there are these general trends of land productivities and ecological suitability in terms of eucalyptus production, local famers and forest policymakers cannot use the general trend as a rule for decision making. For example, the frequently mentioned $24^{\circ}$ north latitude cannot be taken as a reference for policy making, as we can see that there are still obvious variations.

\section{Discussion}

Understanding and predicting ecological suitability for the regional dominant species is crucial for environmental and regional management in the process of organizing land, precipitation, and other resources. This study details the changes in eucalyptus growth in response to various site condition changes. Our findings indicate that: (1) the most important attributes impacting timber yield in order are tree age, stem density, latitude, precipitation, longitude, aspect, regeneration method, plot area, accumulated temperature, altitude, slope, and wood ownership; (2) for management suggestions, the optimal biological rotation period is about 6 years, and the optimal tree density is 1000 stems per hectare. Planting forests and the first-generation coppice tends to experience lower productivity compared to the second and third coppices. Trees owned by state-owned enterprises or overseas companies tend to have better timber yields; (3) considering land suitability, the timber volume falls with increasing altitude. Land below $250 \mathrm{~m}$ generally has above average timber production. Additionally, trees grown on the aspects facing south directions perform better than those facing north. Trees also favor slope degrees of $15-26^{\circ}$; (4) we also help improve the understanding of local famers as well as policymakers who believe that 
eucalyptus plots in the northern area of latitude $24^{\circ}$ tend to have lower productivity due to lower temperature in the mountainous area. Our findings indicate that precipitation shortage, rather than the accumulated temperature decline, is the most restricting factor in affecting timber production. Therefore, $24^{\circ}$ north latitudes cannot be used as a reference for eucalyptus ban policy. Under the conditions of sufficient rainfall, eucalyptus can grow well in the north.

Eucalyptus productivity changes triggered by the variation of key ecological and management factors provide important implications for local farmers and policymakers. One important thing we need to note is that while the model exhibits reasonable behavior, it is likely that our results subject to regional limits and the growth relationships could vary in different countries and continents. Gava and Gonçalves (2008) evaluated the effect of soil attributes on the wood quality of Eucalyptus grandis. They found exponential relations between wood volume and clay content in the State of São Paulo of Brazil [43]. Freitas et al. (2020) found it impossible to isolate or measure all biotic and environment factors that influence eucalyptus productivity on a field scale. Based on 507 eucalyptus stands, they employed artificial neural networks to estimate the mean annual increment of eucalyptus stands and found genotype, spacing, rainfall, temperature, and fertilization were the most predictive variables that influenced eucalyptus growth [44].

In terms of model algorithm, random forest ranks the importance of variables effectively which helps understand the potential biophysical relationship between important predictive variables [45]. Kilham et al. (2018) applied the random-forest algorithm to the selection of forest harvesting and the prediction of forest volume in southeastern Germany and found that the random-forest algorithm was better than the result of generalized linear hybrid model [46]. In order to help forest managers to select the most suitable areas for planting and regeneration, vahedi and Asghar (2016) explored the cork oak suitability assessment based on the random-forest algorithm and generated the cork oak suitability map, which can better help manage the cork oak plantation [47].

Other important caveats are in place. Firstly, we employed a dataset of 4798 sample plots; this is a relatively big dataset for an ecological and management sensitivity study, but as for the regional land productivity prediction, a greater dataset with larger coverage would lead to more robust conclusions. Secondly, the conclusion is derived based on the exclusion of extreme weather conditions, such as a freeze disaster or typhoon. Thirdly, we use information at the centroid of each plantation plot. Converting polygons to points allows the simplification of information extraction and analyses. However, it also leads to a loss of detail. Finally, we use publicly available satellite products. We believe better data quality of certain datasets, such as soil data (if available), would benefit future studies.

Author Contributions: Conceptualization, M.S. and J.X.; methodology, M.S.; software, M.S.; validation, J.X., S.L. and Z.X.; formal analysis, M.S.; investigation, M.S., J.X. and S.L.; resources, J.X., S.L. and Z.X.; data curation, M.S., J.X. and S.L.; writing-original draft preparation, M.S.; writing-review and editing, J.X. and Z.X.; visualization, M.S.; supervision, J.X. and Z.X.; project administration, J.X., M.S. and Z.X.; funding acquisition, M.S. and Z.X. All authors have read and agreed to the published version of the manuscript.

Funding: This study was partly supported by the project of "Science and technology innovation action plan" (grant number: 20692106600) from the Science and Technology Commission of Shanghai Municipality. This study was also financially supported by the Hui Oi-Chow Trust Fund (grant number: 263690561.114525.30900.400.01) of the University of Hong Kong and the National Natural Science Foundation of China (grant number: 42101249). The authors also acknowledge the support of "Fundamental Research Funds for the Central Universities" (grant number: JKE012022006).

Data Availability Statement: Not applicable.

Acknowledgments: The authors of this paper are very grateful for the all-round support of the Guangxi Forestry Department, as well as the strong support of local forest farms. We also thankWuming Hongying fertilizer Co., Ltd. (Nanning, China), Stora Enso (Guangxi) (Beihai, China) and Guangxi Jingui Pulp \& Paper Co., Ltd. (Qinzhou, China) for their knowledge support. 
Conflicts of Interest: The authors declare no conflict of interest. The funders had no role in the design of the study; in the collection, analyses, or interpretation of data; in the writing of the manuscript, or in the decision to publish the results.

\section{References}

1. Chhatre, A.; Agrawal, A. Trade-offs and synergies between carbon storage and livelihood benefits from forest commons. Proc. Natl. Acad. Sci. USA 2009, 106, 17667-17670. [CrossRef] [PubMed]

2. Evaristo, J.; McDonnell, J.J. RETRACTED ARTICLE: Global analysis of streamflow response to forest management. Nature 2019, 570, 455-461. [CrossRef] [PubMed]

3. Anderegg, W.R.L.; Konings, A.; Trugman, A.T.; Yu, K.; Bowling, D.R.; Gabbitas, R.; Karp, D.S.; Pacala, S.; Sperry, J.S.; Sulman, B.; et al. Hydraulic diversity of forests regulates ecosystem resilience during drought. Nature 2018, 561, 538-541. [CrossRef] [PubMed]

4. $\quad$ Bowler, D.E.; Buyung-Ali, L.M.; Healey, J.R.; Jones, J.P.; Knight, T.M.; Pullin, A.S. Does community forest management provide global environmental benefits and improve local welfare? Front. Ecol. Environ. 2012, 10, 29-36. [CrossRef]

5. Isbell, F.; Adler, P.R.; Eisenhauer, N.; Fornara, D.; Kimmel, K.; Kremen, C.; Letourneau, D.K.; Liebman, M.; Polley, H.; Quijas, S.; et al. Benefits of increasing plant diversity in sustainable agroecosystems. J. Ecol. 2017, 105, 871-879. [CrossRef]

6. Schuldt, A.; Ebeling, A.; Kunz, M.; Staab, M.; Guimarães-Steinicke, C.; Bachmann, D.; Buchmann, N.; Durka, W.; Fichtner, A.; Fornoff, F.; et al. Multiple plant diversity components drive consumer communities across ecosystems. Nat. Commun. 2019, 10, 1-11. [CrossRef]

7. Rockwood, D.L.; Rudie, A.W.; Ralph, S.A.; Zhu, J.Y.; Winandy, J.E. Energy Product Options for Eucalyptus Species Grown as Short Rotation Woody Crops. Int. J. Mol. Sci. 2008, 9, 1361-1378. [CrossRef]

8. Forrester, D.I.; Bauhus, J.; Cowie, A.; Vanclay, J. Mixed-species plantations of Eucalyptus with nitrogen-fixing trees: A review. For. Ecol. Manag. 2006, 233, 211-230. [CrossRef]

9. Huang, C.; Huang, D.; Liu, Y.; Qin, W.M.; Huang, G.Y.; Li, B.P. Effect of Plantation and Reestablishment of Two Short-Cycled Types of Industrial Timber Forests on Forest Micrometeorology. J. Ecol. Rural. Environ. 2009, 25, 25-29.

10. Morris, J.; Ningnan, Z.; Zengjiang, Y.; Collopy, J.; Daping, X. Water use by fast-growing Eucalyptus urophylla plantations in southern China. Tree Physiol. 2004, 24, 1035-1044. [CrossRef]

11. Ahmed, R.; Hoque, A.T.M.R.; Hossain, M.K. Allelopathic effects of leaf litters of Eucalyptus camaldulensis on some forest and agricultural crops. J. For. Res. 2008, 19, 19-24. [CrossRef]

12. Whitehead, D.; Beadle, C.L. Physiological regulation of productivity and water use in Eucalyptus: A review. For. Ecol. Manag. 2004, 193, 113-140. [CrossRef]

13. Dye, P. A review of changing perspectives on Eucalyptus water-use in South Africa. For. Ecol. Manag. 2013, 301, 51-57. [CrossRef]

14. Mokochinski, J.B.; Mazzafera, P.; Sawaya, A.C.H.F.; Mumm, R.; De Vos, R.C.H.; Hall, R. Metabolic responses of Eucalyptus species to different temperature regimes. J. Integr. Plant Biol. 2018, 60, 397-411. [CrossRef] [PubMed]

15. Pretzsch, H. Forest Dynamics, Growth, and Yield, in Forest Dynamics, Growth and Yield: From Measurement to Model; Springer: Heidelberg/Berlin, Germany, 2009; pp. 1-39.

16. Muller-Landau, H.C.; Condit, R.S.; Chave, J.; Thomas, S.C.; Bohlman, S.A.; Bunyavejchewin, S.; Davies, S.; Foster, R.; Gunatilleke, S.; Gunatilleke, N.; et al. Testing metabolic ecology theory for allometric scaling of tree size, growth and mortality in tropical forests. Ecol. Lett. 2006, 9, 575-588. [CrossRef]

17. Varian, H.R. Big Data: New Tricks for Econometrics. J. Econ. Perspect. 2014, 28, 3-28. [CrossRef]

18. Mullainathan, S.; Spiess, J. Machine Learning: An Applied Econometric Approach. J. Econ. Perspect. 2017, 31, 87-106. [CrossRef]

19. Crisci, C.; Ghattas, B.; Perera, G. A review of supervised machine learning algorithms and their applications to ecological data. Ecol. Model. 2012, 240, 113-122. [CrossRef]

20. Huang, G.-B.; Zhu, Q.-Y.; Siew, C.-K. Extreme learning machine: Theory and applications. Neurocomputing 2006, 70, 489-501. [CrossRef]

21. Dietterich, T.G. Ensemble Methods in Machine Learning; Springer: Heidelberg/Berlin, Germany, 2000; pp. 1-15.

22. Jordan, M.I.; Mitchell, T.M. Machine learning: Trends, perspectives, and prospects. Science 2015, 349, 255-260. [CrossRef]

23. Athey, S. Machine Learning and Causal Inference for Policy Evaluation. In Proceedings of the 21th ACM SIGKDD International Conference on Knowledge Discovery and Data Mining, Sydney, Australia, 10-13 August 2015; Association for Computing Machinery (ACM): New York, NY, USA, 2015; pp. 5-6.

24. Breiman, L. Random Forests. Mach. Learn. 2001, 45, 5-32. [CrossRef]

25. Sheykhmousa, M.; Mahdianpari, M.; Ghanbari, H.; Mohammadimanesh, F.; Ghamisi, P.; Homayouni, S. Support vector machine versus random forest for remote sensing image classification: A meta-analysis and systematic review. IEEE J. Sel. Top. Appl. Earth Obs. Remote Sens. 2020, 13, 6308-6325. [CrossRef]

26. Kim, Y.; Wojciechowski, R.; Sung, H.; A Mathias, R.; Wang, L.; Klein, A.P.; Lenroot, R.K.; Malley, J.; E Bailey-Wilson, J. Evaluation of random forests performance for genome-wide association studies in the presence of interaction effects. BMC Proc. 2009, 3, S64. [CrossRef] [PubMed]

27. Strobl, C.; Boulesteix, A.-L.; Zeileis, A.; Hothorn, T. Bias in random forest variable importance measures: Illustrations, sources and a solution. BMC Bioinform. 2007, 8, 25. [CrossRef] [PubMed] 
28. Wright, M.; Ziegler, A.; König, I.R. Do little interactions get lost in dark random forests? BMC Bioinform. 2016, 17, 1-10. [CrossRef]

29. Apley, D.W.; Zhu, J. Visualizing the effects of predictor variables in black box supervised learning models. J. R. Stat. Soc. Ser. B Stat. Methodol. 2020, 82, 1059-1086. [CrossRef]

30. Apley, D. Accumulated Local Effects (ALE) Plots and Partial Dependence (PD) Plots, R Package Version 1. 2018. Available online: https:/ / cran.r-project.org/web/packages/ALEPlot/ALEPlot.pdf (accessed on 22 May 2018).

31. Bischl, B.; Lang, M.; Kotthoff, L.; Schiffner, J.; Richter, J.; Studerus, E.; Casalicchio, G.; Jones, Z.M. mlr: Machine Learning in R. J. Mach. Learn. Res. 2016, 17, 1-5.

32. Liaw, A.; Wiener, M. Classification and Regression by randomForest. $R$ News 2002, 2, 18-22.

33. Pebesma, E.J.; Bivand, R.S. Classes and methods for spatial data in R. R News 2005, 5, 9.

34. Roger, S.B.; Edaer, P.; Virgilio, G.-R. Applied Spatial Data Analysis with R, 2nd ed.; Springer: New York, NY, USA, 2013.

35. Wickham, H. Ggplot2: Elegant Graphics for Data Analysis, 2nd ed.; Springer: Cham, Switzerland, 2016 ; ISBN 9783319242774.

36. Zomer, R.J.; Trabucco, A.; Bossio, D.A.; VanStraaten, O.; Verchot, L.V. Climate change mitigation: A spatial analysis of global land suitability for clean development mechanism afforestation and reforestation. Agric. Ecosyst. Environ. 2008, 126, 67-80. [CrossRef]

37. Liu, Y.-S.; Wang, J.-Y.; Guo, L.-Y. GIS-Based Assessment of Land Suitability for Optimal Allocation in the Qinling Mountains, China. Pedosphere 2006, 16, 579-586. [CrossRef]

38. Uy, P.D.; Nakagoshi, N. Application of land suitability analysis and landscape ecology to urban greenspace planning in Hanoi, Vietnam. Urban For. Urban Green. 2008, 7, 25-40. [CrossRef]

39. Reed, P.; Brown, G. Values Suitability Analysis: A Methodology for Identifying and Integrating Public Perceptions of Ecosystem Values in Forest Planning. J. Environ. Plan. Manag. 2003, 46, 643-658. [CrossRef]

40. Gillis, M.D.; Omule, A.Y.; Brierley, T. Monitoring Canada's forests: The National Forest Inventory. For. Chron. 2005, 81, $214-221$. [CrossRef]

41. Zeng, W.; Tomppo, E.; Healey, S.P.; Von Gadow, K. The national forest inventory in China: History-results-international context. For. Ecosyst. 2015, 2, 23. [CrossRef]

42. Mitchell, M.W. Bias of the Random Forest Out-of-Bag (OOB) Error for Certain Input Parameters. Open J. Stat. 2011, 01, 205-211. [CrossRef]

43. Gava, J.L.; Gonçalves, J.L.M. Soil attributes and wood quality for pulp production in plantations of Eucalyptus grandis clone. Sci. Agricola 2008, 65, 306-313. [CrossRef]

44. de Freitas, E.C.S.; de Paiva, H.N.; Neves, J.C.L.; Marcatti, G.E.; Leite, H.G. Modeling of eucalyptus productivity with artificial neural networks. Ind. Crop. Prod. 2020, 146, 112149. [CrossRef]

45. Kilham, P.; Hartebrodt, C.; Kändler, G. Generating Tree-Level Harvest Predictions from Forest Inventories with Random Forests. Forests 2018, 10, 20. [CrossRef]

46. Khalyani, A.H.; Falkowski, M.; Mayer, A. Classification of Landsat images based on spectral and topographic var-iables for land-cover change detection in Zagros forests. Int. J. Remote Sens. 2012, 33, 6956-6974. [CrossRef]

47. Vahedi, A.A. Artificial neural network application in comparison with modeling allometric equations for predicting above-ground biomass in the Hyrcanian mixed-beech forests of Iran. Biomass Bioenergy 2016, 88, 66-76. [CrossRef] 